\title{
Effect of L-arginine on HSP70 expression in liver in weanling piglets
}

\author{
Xin $\mathrm{Wu}^{1,2}$, Chunyan $\mathrm{Xie}^{1 \dagger}$, Yulong Yin ${ }^{1,2,3^{*}}$, Fengna $\mathrm{Li}^{1}$, Tiejun $\mathrm{Li}^{1}$, Ruilin Huang ${ }^{1}$, Zheng Ruan ${ }^{2}$ and Zeyuan Deng ${ }^{2}$
}

\begin{abstract}
Background: This study was conducted to evaluate the effects of L-arginine (Arg) on photomicrographs and HSP70 expression in the liver of weanling piglets. Twelve healthy Landrace $\times$ Yorkshire piglets that had been weaned at $21 \mathrm{~d}$ (average body weight $5.56 \pm 0.51 \mathrm{~kg}$ ) were randomly divided into a control group and an Arg group ( $6 \mathrm{~g} / \mathrm{kg}$ feed). At age $28 \mathrm{~d}$, all of the piglets were slaughtered to obtain liver samples to determine HSP70 expression by real-time PCR, western blot and immunohistochemistry.

Results: The results showed that, compared to control piglets, treatment with Arg decreased inflammatory reactions caused by weaning. The immunohistochemical localization of HSP70 in liver revealed strong expression in the Arg group. Arg increased HSP70 mRNA and HSP70 expression in the liver $(P<0.05)$.

Conclusions: These findings suggest that dietary supplementation with Arg could maintain liver health by inducing HSP70 expression in weanling piglets.

Keywords: L-arginine, Liver, HSP70, Weanling piglets
\end{abstract}

\section{Background}

As the largest internal organ, the liver is responsible for about 500 vital bodily functions, and plays important roles in digestion and metabolism by regulating the production, storage, and release of sugar, fats, and cholesterol. The liver produces a variety of important proteins, including enzymes, hormones, blood proteins, clotting factors, and immune factors. As the main site of detoxification and the primary defense barrier, the liver is liable to be injured by weaning stress [1]. Weaning stress in piglets is often associated with reduced food consumption as well as temporary reductions in weight gain, which can result in postweaning lag, a period of decreased feed intake and increased diarrhea, disease, intestinal dysfunction and atrophy, and mortality in piglets [2-6]. A healthy liver can produce approximately 80 percent of the body's required

\footnotetext{
* Correspondence: yyulong2003@yahoo.com.cn

${ }^{\dagger}$ Equal contributors

${ }^{1}$ Scientific Observing and Experimental Station of Animal Nutrition and Feed Science in South-Central, Ministry of Agriculture, Hunan Provincial Engineering Research Center of Healthy Livestock, Key Laboratory of Agro-ecological Processes in Subtropical Region, Institute of Subtropical Agriculture, Chinese Academy of Sciences, Changsha, Hunan 410125, China ${ }^{2}$ State Key Laboratory of Food Science and Technology and College, Nanchang University, Nanchang 330031, China

Full list of author information is available at the end of the article
}

amino acids, among which L-arginine (Arg) is essential; when Arg turnover increases, as in growth, inflammation, or tissue repair, the dietary supply can become ratelimiting for Arg-metabolizing pathways [7-10]. Arg deficiency can result in hyperammonemia, and intestinal and immunological dysfunction [11,12]. The administration of Arg reduces damage to liver tissue after ischaemia injury [13]. Urea synthesis from primary hepatocytes seems to be a valid viability indicator, since mitochondrial transmembrane transport of the urea cycle intermediates ornithine and citrulline is involved in the urea cycle [14].

Heat shock protein 70 (HSP70) is a member of a highly conserved family that possess a variety of functions, but are best known for chaperoning and re-folding partially denatured protein [15-17]. The hepatic response to stress may involve the synthesis and accumulation of HSP70s $[18,19]$. Experimental evidence suggests that some amino acids such as glutamine and arginine regulate HSP expression, which is essential for preventing organ dysfunction [20]. The aim of the present study was to investigate the effects of Arg on photomicrographs and HSP70 expression in the liver under weaning stress in piglets.

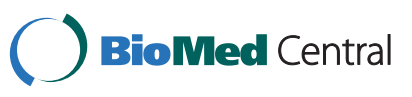

(C) 2013 Wu et al.; licensee BioMed Central Ltd. This is an Open Access article distributed under the terms of the Creative Commons Attribution License (http://creativecommons.org/licenses/by/2.0), which permits unrestricted use, distribution, and reproduction in any medium, provided the original work is properly cited. 


\section{Methods}

Animals, housing and treatments

Twelve healthy Landrace $\times$ Yorkshire piglets weaned at $21 \mathrm{~d}$ (average weight $5.56 \pm 0.51 \mathrm{~kg}$ ) were randomly divided into a control group and an Arg group (6 g/ kg feed). The diet in the control group was made isonitrogenous with the addition of appropriate amounts of alanine $(12.3 \mathrm{~g} / \mathrm{kg}$ feed $)$ at the expense of lactose and glucose, as described by Kim et al. [21]. The nutrients in the basal diet were adequate for piglets to meet the NRC-recommended requirements within the weight range used in the present study [22]. The main ingredients in the basal diet were corn $(51.55 \mathrm{~g} / \mathrm{kg})$, soybean meal $(242 \mathrm{~g} / \mathrm{kg})$, fishmeal $(60 \mathrm{~g} / \mathrm{kg})$, whey powder $(90 \mathrm{~g} / \mathrm{kg})$, and cream (EE 50\%, $60 \mathrm{~g} / \mathrm{kg}$ ) (Table 1). The diets were balanced with respect to the standardized content of DE $(14.2 \mathrm{MJ} / \mathrm{kg}), \mathrm{CP}(200 \mathrm{~g} / \mathrm{kg})$, true ileal digestible limiting amino acids (Lys, Met + Cys, Thr, Trp), Ca and P, according to our previous study [23]. The diets were administered three times daily at 08:00, 12:00, and 18:00, respectively. All of the animals had free access to drinking water.

Arg was obtained from Ajinomoto (Tokyo, Japan).

The experiment was carried out in accordance with the Chinese Guidelines for Animal Welfare and approved by the Animal Welfare Committee of the Institute of Subtropical Agriculture, the Chinese Academy of Sciences.

\section{Sampling}

At age $28 \mathrm{~d}$, blood samples were obtained for the analysis of serum indices. All of the experimental piglets were anaesthetised with an i.v injection of sodium pentobarbital (50 mg/kg BW) and bled by exsanguination. Liver samples were rapidly frozen in liquid nitrogen and stored at -80 for real-time PCR and Western blotting analysis. Additional liver samples from the same location were fixed in $4 \%$ paraformaldehyde for two hours at 4, transferred to PBS overnight and 30\% sucrose for 2 hours at 4, and then embedded in paraffin, sectioned, and stained with hematoxylin and eosin for histologic studies. The histological activity index (HAI) were evaluated according to Ishak and colleagues [24].

\section{Serum biochemical indices}

An Automated Biochemistry Analyzer (Synchron CX Pro, Beckman Coulter, Fullerton, CA, USA) was used to determine the concentrations of serum glucose, glutamicoxalacetic transaminase (GOT), glutamic-pyruvic transaminase (GPT), lactic acid (LAC), lactate dehydrogenase (LDH), and alkaline phosphatase (ALP) activities, according to commercial kits and the manufacturer's instructions. All kits were purchased from Beijing Chemlin Biotech Co., Ltd (Beijing, China).
Table 1 Composition of the basal diet for weanling pigs (as-fed basis)

\begin{tabular}{|c|c|c|}
\hline & Control group & Arg group \\
\hline \multicolumn{3}{|l|}{ Ingredients (\%) } \\
\hline Corn $\left(8 \% \mathrm{CP} ;<13 \% \mathrm{H}_{2} \mathrm{O}\right)$ & 49.9 & 49.9 \\
\hline Soybean expanded (43\% CP) & 24.2 & 24.2 \\
\hline Fish meal (CP 65\%) & 6.0 & 6.0 \\
\hline Whey (100\%) & 9.0 & 9.0 \\
\hline Cream powder (50\% fat) & 6.0 & 6.0 \\
\hline Limestone & 0.5 & 0.5 \\
\hline Monocalcium phosphate & 1.0 & 1.0 \\
\hline $\mathrm{NaCl}$ & 0.2 & 0.2 \\
\hline Flavor & 0.06 & 0.06 \\
\hline Mineral-vitamin premix ${ }^{1}$ & 1.0 & 1.0 \\
\hline L-Lysine $\cdot \mathrm{HCl}$ & 0.31 & 0.31 \\
\hline L-Methionine & 0.06 & 0.06 \\
\hline L-Threonine & 0.12 & 0.12 \\
\hline Glucose & 0.42 & 1.05 \\
\hline L-alanine & 1.23 & 0.0 \\
\hline L-Arginine & 0.0 & 0.6 \\
\hline Total & 100 & 100 \\
\hline \multicolumn{3}{|l|}{ Nutrient levels ${ }^{2}$} \\
\hline $\mathrm{DE}(\mathrm{MJ} / \mathrm{kg})$ & 14.21 & 14.21 \\
\hline Crude protein (\%) & 20.0 & 20.0 \\
\hline Calcium (\%) & 0.71 & 0.71 \\
\hline Available phosphorus (\%) & 0.48 & 0.48 \\
\hline L-Lysine (\%) & 1.35 & 1.35 \\
\hline L-Methionine (\%) & 0.39 & 0.39 \\
\hline L-Threonine (\%) & 0.91 & 0.91 \\
\hline L-Arginine (\%) & 0.49 & 1.09 \\
\hline
\end{tabular}

${ }^{1}$ Providing the following per kg diet: $\mathrm{CuSO}_{4} \cdot 5 \mathrm{H}_{2} \mathrm{O}, 19.8 \mathrm{mg} ; \mathrm{Kl}, 0.20 \mathrm{mg}$; $\mathrm{FeSO}_{4} \cdot 7 \mathrm{H}_{2} \mathrm{O}, 400 \mathrm{mg} ; \mathrm{NaSeO}_{3}, 0.56 \mathrm{mg} ; \mathrm{ZnSO}_{4} \cdot 7 \mathrm{H}_{2} \mathrm{O}, 359 \mathrm{mg} ; \mathrm{MnSO}_{4} \cdot \mathrm{H}_{2} \mathrm{O}$, $10.2 \mathrm{mg}$; vitamin $\mathrm{K}$ (menadione), $5 \mathrm{mg}$; vitamin $\mathrm{B}_{1}, 2$ mg; vitamin $\mathrm{B}_{2}, 15 \mathrm{mg}$; vitamin $B_{12}, 30 \mu$; vitamin $A, 5400 \mathrm{IU}$; vitamin $D_{3}, 110 \mathrm{IU}$; vitamin $\mathrm{E}, 18 \mathrm{IU}$; choline chloride, $80 \mathrm{mg}$; antioxidants, $20 \mathrm{mg}$; Fungicide $100 \mathrm{mg}$.

${ }^{2}$ Chemical composition was calcualted and not analyzed.

Serum cortisol (COR) was determined by radioimmunoassay according to the instructions of the manufacturer of the corresponding reagent kit (China Institute of Atomic Energy, Beijing, China).

\section{Immunohistochemistry for HSP70}

Paraffin-embedded liver tissue samples were processed using an immunohistochemical technique with specific anti-HSP70 (SPA-810 Stressgen Bioreagents, British Columbia, Canada) diluted 1:400 using PBS buffer. Samples were subjected to antigen retrieval and the reduction of non-specific binding. The tissue sections were incubated with primary antibody in a humidified chamber at $4^{\circ} \mathrm{C}$. After the tissue sections were rinsed with 
Tris buffered saline (TBS), $\mathrm{pH}$ 7.4, they were incubated at room temperature for $30 \mathrm{~min}$ for the detection of HSP70. The BCIP-NBT substrate system (Sigma, St. Louis, $\mathrm{MO}$ ) was used to detect alkaline phosphatase conjugate activity. The sections were then counterstained with haematoxylin for $5 \mathrm{~s}$, and then rinsed, dried and mounted with coverslips. The sections were examined by light microscopy and images were captured with a digital camera.

\section{Real-time PCR for HSP70}

Total RNA was extracted from liver tissue by a guanidinium isothiocyanate method using TrizolTM reagent (Gibco BRL, Berlin, Germany) and treated with DNase according to the manufacturer's instructions. The mRNA of HSP70 was determined by a standard real-time polymerase chain reaction (PCR) method as previously described [25]. The following primer pairs were used: GAPDH: (Fwd-5'-GTCGGTGTGAACG GATTT-3'; Rev-5'-ACTCCACGACGTACTCAGC-3') and HSP70 (Fwd-5'-GCCCTGAATCCGCAGAATA-3'; Rev-5'-TCCCCACGGTAGGAAACG-3') based on the following conditions: $30 \mathrm{~s}$ of denaturation at 94, $30 \mathrm{~s}$ of annealing at 56, and $30 \mathrm{~s}$ of extension at 72 for 30 cycles.

\section{Western blot for HSP70}

To confirm the results of immunohistochemistry, the expression of HSP70 in the liver was detected by Western blot assay. Western blot analysis was performed as described previously [26], with GAPDH as a loading control. One hundred-microgram samples were homogenized in 6 volumes of buffer A $(20 \mathrm{mM}$ HEPES, pH 7.4, 100 mM KCl, 0.2 mM EDTA, 2 mM EGTA, $1 \mathrm{mM}$ DTT, $50 \mathrm{mM}$ NaF, $50 \mathrm{mM} \beta$-glycerolphosphate, $0.1 \mathrm{mM}$ PMSF, $1 \mathrm{mM}$ benzamidine, $0.5 \mathrm{mM}$ sodium vanadate, and $1 \mu \mathrm{M}$ microcystin LR) and centrifuged at 10,000 $\mathrm{g}$ for $10 \mathrm{~min}$ at 4 . The pellet was discarded and the supernatant was aliquoted into microcentrifuge tubes. The protein content was quantified using a detergent-compatible protein assay kit (Bio-Rad), and aliquots of $10 \mu \mathrm{g}$ were taken individually from each sample, mixed with a one-fifth volume of the sample buffer [0.35 M Tris-Cl, $\mathrm{pH} 6.8$, 10\% SDS, 30\% glycerol, 9.3\% dithiothreitol (DTT), and $0.175 \mathrm{mM}$ bromophenol blue], and then heat-denatured by boiling for $5 \mathrm{~min}$. Separated proteins were transferred to polyvinylidene difluoride membranes (Immobilon-P, Millipore, Bedford, MA) overnight at 4, and then incubated with a blocking solution (0.05\% Tween 20, $50 \mathrm{mM}$ Tris, $\mathrm{pH} 8.0,150 \mathrm{mM} \mathrm{NaCl}$, and $5 \%$ powdered nonfat milk) for $1 \mathrm{~h}$. Membranes were then incubated in a 1:500 dilution of monoclonal antibody raised against HSP70 diluted 1:3000 for two hours at room temperature. Similar treatment of the same blot sheet was performed using rabbit polyclonal anti-GAPDH antibody diluted
1:5000 (CSA-400 Stressgen Bioreagents, British Columbia, Canada) after the first antibody treatment had been stripped off. The membrane was incubated with appropriate peroxidase-labeled secondary antibody prepared in PBS-Tween 20. Membranes were then washed and incubated in the goat anti-rabbit secondary antibody (horseradish peroxidase-conjugated goat anti-mouse, Zhongsan Golden Bridge, China) at a 1:5000 dilution at room temperature for $2 \mathrm{~h}$. Primary antibody binding was visualized using an enhanced chemiluminescence kit (Pierce, Rockford, IL) and Hyperfilm-MP (Amersham International, Buckinghamshire, UK).

Immunohistochemical staining was performed on an Alpha Innotech (San Leandro, CA) 8800 image station with FLUORCHEM software using enhanced chemiluminescence (ECL) as the chromagen. The relative intensities of the Western blot membranes were compared using Alpha Ease software.

\section{Statistical analysis}

The data were analyzed by Student's T-test, with the significance level set at 0.05 . A P-value of $\mathrm{P}>0.05$ but $\mathrm{P}<0.1$ was taken to indicate a trend. Data are presented as the mean \pm standard error.

\section{Results}

\section{Effect of Arg on liver weight and serum biochemical} indices

The liver tended to be heavy in the Arg group $(\mathrm{P}=0.071)$ (Figure 1). Compared to the control piglets, Arg increased serum ALP $(\mathrm{P}<0.05)$, and decreased GOT $(\mathrm{P}<0.05)$, lactic acid $(\mathrm{P}<0.05)$ and $C O R(P<0.05)$. Arg did not affect GLU or amylase $(P>0.05)$.

\section{Effects of Arg on pathological findings}

Histopathological changes such as sinusoidal dilatation, hepatocellular vacuolization and hepatocellular necrosis were present. Moderate cell infiltration was seen in the periportal areas. Histopathologic examination showed increases in lymphocyte and neutrophil infiltration in the central and portal areas in the livers of the control group. In some areas, microvesicular steatosis and hepatocyte degeneration were also observed. Hepatic ischaemia was seen in the control groups. In the Arg group, inflammatory reactions were decreased and other changes were almost absent in liver sections (Figure 1). HAI was lower in the Arg group $(P<0.05)$ (Table 2$)$.

\section{Immunohistochemistry, real-time PCR, and Western blot for HSP70 in liver}

Immunohistochemistry studies showed different behaviors of HSP70 expression. The immunohistochemical localization of HSP70 in the liver revealed stronger expression in the Arg group (Figure 2). 

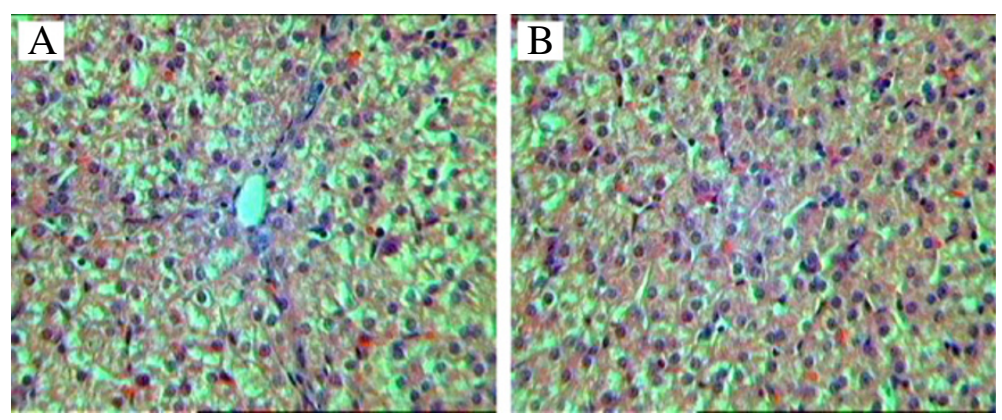

Figure 1 Photomicrographs of control group (A) and Arg group (B). Original magnification, 400X.

Real-time PCR showed that the level of HSP70 mRNA in the liver was higher in the $\operatorname{Arg}$ group $(P<0.05)$ (Figure 3). To confirm the results of immunohistochemistry, liver tissues were subjected to Western blot assay. Representative results are shown in Figure 3. The expression of HSP70 in the control group was lower than that in the $\operatorname{Arg}$ group $(P<0.05)$.

\section{Discussion}

In rodents and humans, Arg is essential when Arg turnover increases, as in growth, inflammation, or tissue repair, and the dietary supply can become rate-limiting for Arg-metabolizing pathways [7,27]. Indeed, low Arg levels have been documented in weaning-age piglets [21]. It has been reported that, compared to that in newborn pigs, the intestinal synthesis of citrulline and Arg from glutamine and glutamate decreases by $70-73 \%$ in 7-d-old suckling pigs, and declines further in 14- to 21-d-old pigs [7].

In the present study, the significant increase in serum $\mathrm{COR}$ and the marked decrease in ALP in the control

Table 2 Effects of Arg on liver weight and serum biochemical indices in weanling piglets $(n=6)$

\begin{tabular}{lll}
\hline Items & Control & Arg \\
\hline Initial body weight $(\mathrm{kg})$ & $5.9 \pm 0.4$ & $5.9 \pm 0.4$ \\
Final body weight $(\mathrm{kg})$ & $6.1 \pm 0.3^{\mathrm{a}}$ & $6.6 \pm 0.3^{\mathrm{b}}$ \\
Feed intake daily $(\mathrm{g})$ & $158.3 \pm 20.9^{\mathrm{a}}$ & $180.6 \pm 29.3^{\mathrm{b}}$ \\
Liver weight $(\mathrm{kg})$ & $140.9 \pm 5.0$ & $143.9 \pm 5.2$ \\
Liver weight/Body weight $(\%)$ & $2.3 \pm 0.1$ & $2.18 \pm 0.1$ \\
Glucose (mmol/L) & $7.7 \pm 1.0$ & $6.9 \pm 0.6$ \\
Glutamic-oxalacetic transaminase $(\mathrm{mmol} / \mathrm{L})$ & $46.3 \pm 10.5^{\mathrm{a}}$ & $34.5 \pm 6.2^{\mathrm{b}}$ \\
Glutamic pyruvic transaminase $(\mathrm{mmol} / \mathrm{L})$ & $43.0 \pm 5.8$ & $45.2 \pm 4.9$ \\
Alkaline phosphatase (mmol/L) & $166.8 \pm 50.5^{\mathrm{a}}$ & $224.2 \pm 36.6^{\mathrm{b}}$ \\
Lactic acid (mmol/L) & $69.8 \pm 12.9^{\mathrm{a}}$ & $41.2 \pm 11.1^{\mathrm{b}}$ \\
Lactate dehydrogenase $(\mathrm{U} / \mathrm{L})$ & $597.8 \pm 69.0$ & $546.5 \pm 86.3$ \\
Cortisol ( $\mu \mathrm{gg} / \mathrm{L})$ & $88.7 \pm 26.1^{\mathrm{a}}$ & $69.6 \pm 22.7^{\mathrm{b}}$ \\
\hline
\end{tabular}

ab: means in the same row with different letters differ significantly $(P<0.05)$. Values are means \pm standard error. group indicated that weaning caused stress in piglets, and the elevation of AST in serum may indicate that the liver was damaged. Accordingly, the present results indicated that Arg decreased damage to liver tissue after weaning, in comparison to the control group. This is consistent with the results of other studies. For example, the administration of Arg reduces damage to liver tissue after ischaemia injury [13]. In addition, it has been reported that Arg could protect rats with liver cirrhosis from acute ammonia intoxication [28].

HSPs are intracellular chaperones that play a key role in the recovery from stress and are involved in nearly all intracellular compartments. Stress-induced HSP70s function to promote refolding and prevent the aggregation of partially-denatured proteins, as well as tag irreversiblydamaged proteins for proteolysis [29]. Arg deprivation decreases HSP expression, and enhances the cellular susceptibility to apoptosis [30]. HSP70 could be used as a marker for assessing the biological behavior under stress in vivo [31]. It has been reported that the overexpression of liver HSP70, particularly during the summer, may confer differential effects on cell survival by protecting against changes induced by oxidative stress [32]. Our results suggest that Arg increased HSP70 mRNA and protein in the liver. Accordingly, immunohistochemistry studies showed differences in HSP70 expression. Our study demonstrated that the

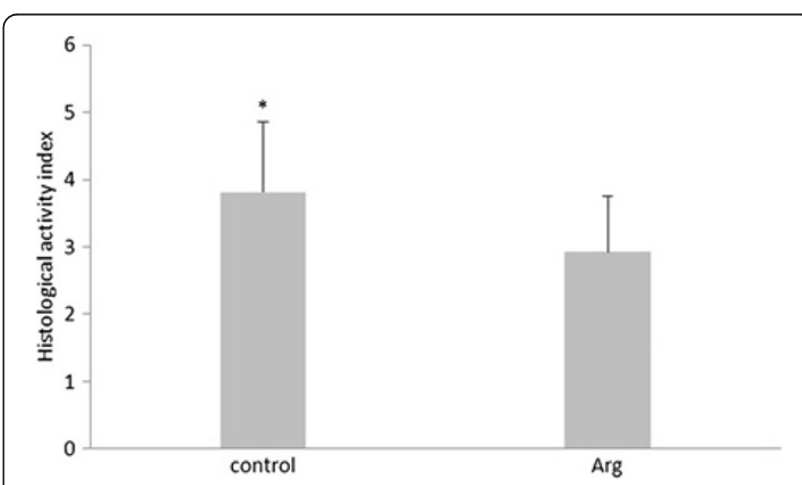

Figure 2 Effect of Arg on histological activity index of piglets. 

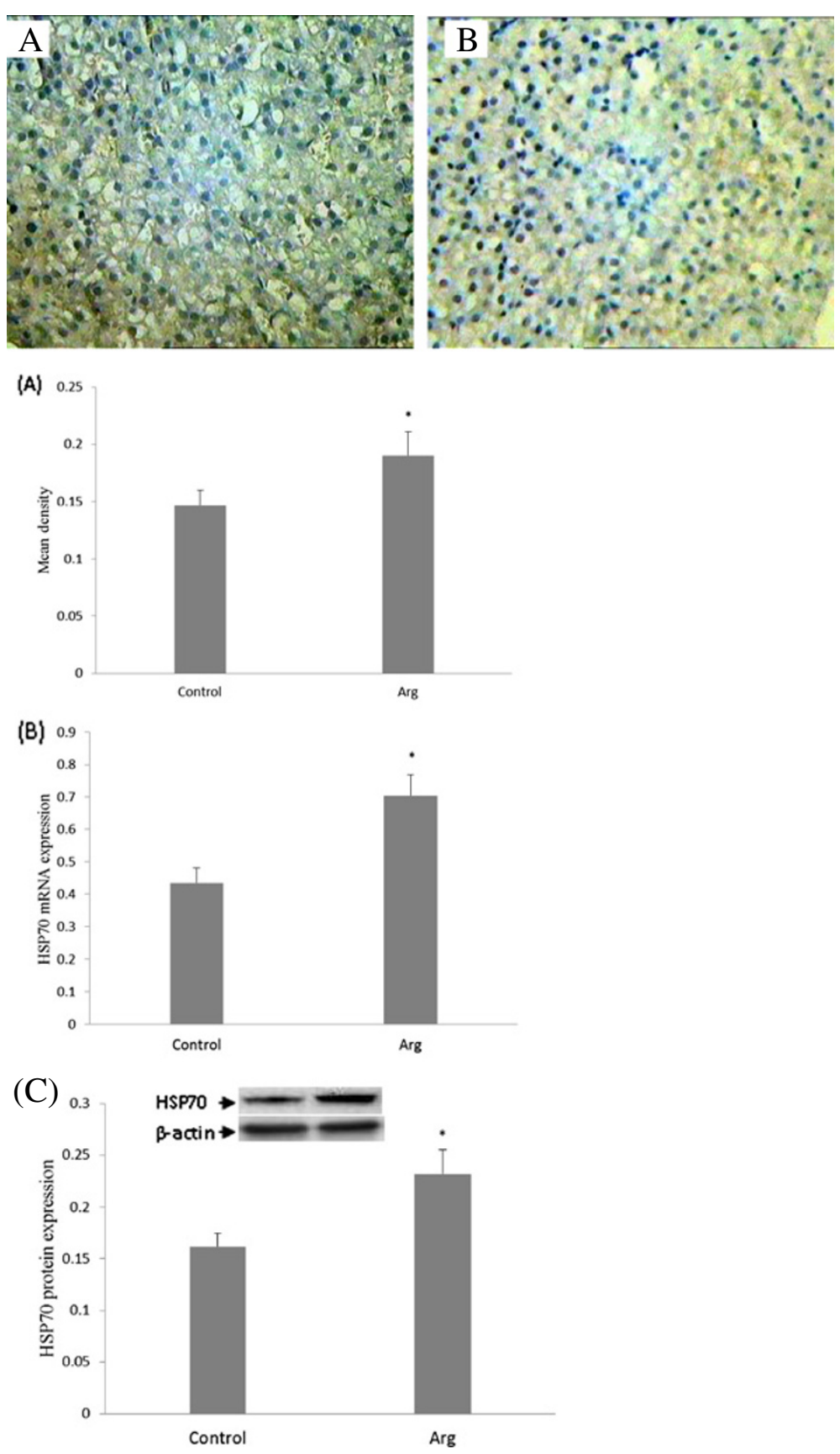

Figure 3 Immunohistochemistry (A), Real-time PCR (B) and Western blot (C) analysis for HSP70 and $\beta$-actin expression in liver tissues. HSP70 expression showed positive and statistically significant correlation with favorable prognosis. A (control group) showed expression of HSP70 staining; B stronger expression of HSP70 was observed in the B (Arg group). Original magnification 400x. $(n=6)$. Both HSP70 mRNA and protein were higher in the Arg group $(P<0.05)$.

expression of HSP70 in the liver was negatively correlated with an increase in the aggressiveness of the histological type. It has also been reported that HSP70 levels in the liver were significantly increased in heatstressed mice that had been administered Arg compared with a heat-stress-only group [20]. If we consider the role of HSP70 in RNA-DNA proliferation, these increases may be explained by an increase in cell proliferation and protein synthesis promoted by supplementation with Arg [33,34].

\section{Conclusions}

In summary, the present results indicated that pretreatment with Arg could increase the expression of HSP70 in 
the liver, which might be able to reduce liver injury and enhance liver health in piglets during weaning.

\section{Competing interests}

The authors declare that they have no competing interest.

\section{Authors' contributions}

$X W$ and $Y Y$ designed the study. XW and CX performed the experiments and analyzed the data. XW prepared the manuscript and all of the authors contributed to, read and approved the final manuscript.

\section{Acknowledgments}

This study was jointly supported by the National Key Technology Research and Development Program of the Ministry of Science and Technology of China (2012BAD39B00), National Basic Research Project (2012CB124704), the NSFC (31101730, 31110103909, 30901040, 30901041), Chinese Academy of Sciences and Knowledge Innovation Project (2012B091100259,

2012B091100210, CXJQ120113), and China Postdoctoral Science Foundation Funded Project (2012 T50592; 20110491493).

\section{Author details}

'Scientific Observing and Experimental Station of Animal Nutrition and Feed Science in South-Central, Ministry of Agriculture, Hunan Provincial Engineering Research Center of Healthy Livestock, Key Laboratory of Agro-ecological Processes in Subtropical Region, Institute of Subtropical Agriculture, Chinese Academy of Sciences, Changsha, Hunan 410125, China. ${ }^{2}$ State Key Laboratory of Food Science and Technology and College, Nanchang University, Nanchang 330031, China. Institute of Subtropical Agriculture, Chinese Academy of Sciences, Changsha, Hunan 410125, China.

Received: 26 November 2012 Accepted: 27 March 2013

Published: 4 April 2013

\section{References}

1. Chen T, Zamora R, Zuckerbraun B, Billiar TR: Role of nitric oxide in liver injury. Curmol med 2003, 3(6):519-526.

2. Lalles JP, Bosi P, Smidt H, Stokes CR: Weaning - A challenge to gut physiologists. Livest Sci 2007, 108(1-3):82-93.

3. Castillo M, Martin-Orue SM, Nofrarias M, Manzanilla EG, Gasa J: Changes in caecal microbiota and mucosal morphology of weaned pigs. Vet Microbiol 2007, 124(3-4):239-247.

4. Boudry G, Peron V, Le Huerou-Luron I, Lalles JP, Seve B: Weaning induces both transient and long-lasting modifications of absorptive, secretory, and barrier properties of piglet intestine. J Nutr 2004, 134(9):2256-2262.

5. Gu X, Li D, She R: Effect of weaning on small intestinal structure and function in the piglet. Arch Tierernahr 2002, 56(4):275-286.

6. Hampson DJ: Alterations in piglet small intestinal structure at weaning. Res Vet Sci 1986, 40(1):32-40.

7. Wu G, Knabe DA, Kim SW: Arginine nutrition in neonatal pigs. J Nutr 2004, 134(10):2783S-2790S. discussion 2796S-2797S.

8. Liu XD, Wu X, Yin YL, Liu YQ, Geng MM, Yang HS, Francois B, Wu GY: Effects of dietary $\mathrm{L}$-arginineor $\mathrm{N}$-carbamylglutamate supplementation during late gestation of sows on the miR-15b/16, miR-221/222, VEGFA and eNOS expression in umbilicalvein. Amino Acids 2012, 42:2111-2119.

9. Ren WK, Luo W, Wu MM, Liu G, Yu XL, Fang J, Li TJ, Yin YL, Wu GY: Dietary L-glutamine supplementation improves pregnancy outcome in mice infected with type-2 porcine circovirus. Amino Acids. doi:10.1007/s00726011-1134-5.

10. Ren WK, Yin YL, Liu G, Yu XL, Li YH, Yang G, Li TJ, Wu GY: Effect of dietary arginine supplementation on reproductive performance of mice with porcine circovirus type 2 (PCV2) infection. Amino Acids 2012, 42:2089-2094

11. Tong BC, Barbul A: Cellular and physiological effects of arginine. Mini Rev Med Chem 2004, 4(8):823-832.

12. Wu G, Jaeger LA, Bazer FW, Rhoads JM: Arginine deficiency in preterm infants: biochemical mechanisms and nutritional implications. J Nutr Biochem 2004, 15(8):442-451.

13. Calabrese F, Valente M, Pettenazzo E, Ferraresso M, Burra P, Cadrobbi R, Cardin R, Bacelle L, Parnigotto A, Rigotti P: The protective effects of Larginine after liver ischaemia/reperfusion injury in a pig model. $J$ Pathol 1997, 183(4):477-485.
14. Satrustegui J, Pardo B, Del Arco A: Mitochondrial transporters as novel targets for intracellular calcium signaling. Physiolrev 2007, 87(1):29-67.

15. Beckmann RP, Mizzen LE, Welch WJ: Interaction of Hsp 70 with newly synthesized proteins: implications for protein folding and assembly. Science 1990, 248(4957):850-854.

16. Johnson JL, Craig EA: Protein folding in vivo: unraveling complex pathways. Cell 1997, 90(2):201-204.

17. Samali A, Orrenius S: Heat shock proteins: regulators of stress response and apoptosis. Cell Stress Chaperones 1998, 3(4):228-236.

18. Gonzalez B, Manso R: Induction, modification and accumulation of HSP70s in the rat liver after acute exercise: early and late responses. J Physiol 2004, 556(Pt 2):369-385.

19. Boeri D, Dondero F, Storace D, Maiello M, Pasqualini M, Pellicci R: Heatshock protein 70 favours human liver recovery from ischaemiareperfusion. Euro J clin invest 2003, 33(6):500-504.

20. Chatterjee S, Premachandran S, Sharma D, Bagewadikar RS, Poduval TB: Therapeutic treatment with $\mathrm{L}$-arginine rescues mice from heat strokeinduced death: physiological and molecular mechanisms. Shock 2005, 24(4):341-347.

21. Kim SW, Wu G: Dietary arginine supplementation enhances the growth of milk-fed young pigs. J Nutr 2004, 134(3):625-630.

22. NRC: Nutrient Requirements of Swine. 10th edition. Washington, DC, USA: National Academy Press; 1998.

23. Wu X, Ruan Z, Gao Y, Yin Y, Zhou X, Wang L, Geng M, Hou Y, Wu G: Dietary supplementation with L-arginine or $\mathrm{N}$-carbamylglutamate enhances intestinal growth and heat shock protein-70 expression in weanling pigs fed a corn- and soybean meal-based diet. Amino Acids 2010, 39(3):831-839.

24. Ishak K, Baptista A, Bianchi L, Callea F, De Groote J, Gudat F, Denk H, Desmet V, Korb G, MacSween RN: Histological Grading and Staging of Chronic Hepatitis. J Hepatol 1995, 22(6):696-699.

25. Yu H, Bao ED, Zhao RQ, Lv QX: Effect of transportation stress on heat shock protein 70 concentration and mRNA expression in heart and kidney tissues and serum enzyme activities and hormone concentrations of pigs. Am J Vet Res 2007, 68(11):1145-1150.

26. Yao K, Yin YL, Chu W, Liu Z, Deng D, Li T, Huang R, Zhang J, Tan B, Wang $W$, et al: Dietary arginine supplementation increases mTOR signaling activity in skeletal muscle of neonatal pigs. J Nutr 2008, 138(5):867-872.

27. Flynn NE, Meininger $\mathrm{CJ}$, Haynes TE, Wu G: The metabolic basis of arginine nutrition and pharmacotherapy. Biomed Pharmacother 2002, 56(9):427-438.

28. Kim W, Park H, Yun C, Cho H, Kim S, Paik W, Jeon S, Lee J: Mixture of Ncarbamoyl-L-glutamate plus L-arginine can protect rats with liver cirrhosis from acute ammonia intoxication. J Hepat 2001, 35(6):719-725.

29. Wu X, Zhang Y, Yin Y, Ruan Z, Yu H, Wu Z, Wu G: Roles of heat-shock protein 70 in protecting against intestinal mucosal damage. Front Biosci 2013, 18:356-365.

30. Lenaerts K, Renes J, Bouwman FG, Noben JP, Robben J, Smit E, Mariman EC: Arginine deficiency in preconfluent intestinal Caco-2 cells modulates expression of proteins involved in proliferation, apoptosis, and heat shock response. Proteomics 2007, 7(4):565-577.

31. Sepponen K, Poso AR: The inducible form of heat shock protein 70 in the serum, colon and small intestine of the pig: comparison to conventional stress markers. Vet J 2006, 171(3):519-524.

32. Padmini E, Vijaya Geetha B: Impact of season on liver mitochondrial oxidative stress and the expression of HSP70 in grey mullets from contaminated estuary. Ecotox (London, England) 2009, 18(3):304-311.

33. Tan BE, Yin YL, Liu ZQ, Li XG, Xu HJ, Kong XF, Huang RL, Tang WJ, Shinzato I, Smith SB, Wu GY: Dietary L-arginine supplementation increases muscle gain and reduces body fat mass in growing-finishing pigs. Amino Acids 2009, 37:169-175.

34. Kong XF, Tan BE, Yin $Y L$, Li XL, Jaeger LA, Bazer FW, Wu GY: Arginine stimulates the mTOR signaling pathway and protein synthesis in porcine trophectoderm cells. J Nutr Biochem 2012, 23(9):1178-1183.

doi:10.1186/1746-6148-9-63

Cite this article as: Wu et al: Effect of L-arginine on HSP70 expression in liver in weanling piglets. BMC Veterinary Research 2013 9:63. 